\title{
A legitimidade do controle social da gestão pública: uma resposta a Herbert Wechsler
}

\author{
Douglas Antônio Rocha Pinheiro \\ Universidade Federal de Goiás / \\ Programa de Pós-Graduação Interdisciplinar em Direitos Humanos \\ Goiânia / GO - Brasil
}

\begin{abstract}
Partindo do questionamento de Herbert Wechsler acerca da pertinência da crítica feita pelo cidadão comum em relação às decisões tomadas pelos governantes, o artigo formula uma resposta interdisciplinar ao jurista por meio da filosofia da responsabilidade, dos pilares da accountability e dos limites do sistema presidencialista com o intuito de legitimar o controle social da gestão pública.

Palavras-chave: accountability; controle social; gestão pública responsável.
\end{abstract}

La legitimidad del control social de la gestión pública: una respuesta a Herbert Wechsler Tomando como punto de partida el cuestionamiento de Herbert Wechsler sobre la pertinencia de la crítica hecha por el ciudadano común con relación a las decisiones adoptadas por los gobernantes, el artículo elabora una respuesta interdisciplinaria al jurista a través de la filosofía de la responsabilidad, de los pilares de la rendición de cuentas y de los límites del sistema presidencial con el fin de legitimar el control social de la gestión pública.

Palabras clave: accountability; control social; gestión pública responsable.

The legitimacy of social control over public management: a response to the views of Herbert Wechsler

Based on Herbert Wechsler's questioning in relation to the appropriateness of criticism by ordinary citizens of the decisions taken by the authorities who govern them, this paper proposes an interdisciplinary response to this particular jurist by using the philosophy of responsibility, the pillars of accountability and the limits of the presidential system in order to legitimize social control over public management.

KEYWORDS: accountability; social control; responsible public management.

DOI: http://dx.doi.org/10.1590/0034-7612148708

Artigo recebido em 17 abr. 2015 e aceito em 18 jul. 2016. 


\section{Introdução}

Em 1955, Herbert Wechsler foi convidado pelo Instituto de Estudos Religiosos e Sociais do Seminário Teológico Judaico da América para proferir uma conferência sobre os dilemas e os deveres da vida de um jurista. Wechsler, professor de direito na Universidade de Columbia, estava em evidência à época por ter publicado dois anos antes, em coautoria com o professor Henry Hart da Universidade de Harvard, uma compilação de sucesso das principais decisões judiciais proferidas pelas Cortes Federais dos Estados Unidos. Na palestra, em meio a conselhos baseados em sua experiência profissional, Wechsler apontou uma distinção entre dois tipos de crítica: a estéril e a responsável, defendendo que a última só se manifesta quando o crítico se coloca "adequadamente na posição do homem cuja decisão pretenda criticar" (Wechsler, 1957:119).

$\mathrm{O}$ ataque à suposta crítica irresponsável não foi uma exclusividade de Wechsler. Aliás, tal postura contou com outros defensores bem mais eminentes na estrutura política estadunidense. Em certa ocasião, John F. Kennedy teria afirmado que só poderia avaliar um presidente da república quem tivesse sentado em sua cadeira, examinado sua correspondência, verificado as informações deixadas sobre sua escrivaninha e estudado o motivo de suas decisões (Donald, 1995:13). Henry Kissinger, por sua vez, relativizara o papel da crítica ao diferenciar os campos de atuação do analista e do político: enquanto o primeiro teria liberdade de escolha do problema a ser estudado e poderia fazê-lo com todo o tempo necessário e sem riscos, pois diante da não comprovação de suas hipóteses sempre haveria a possibilidade de reescrita, o segundo teria que lidar com problemas impostos pelas circunstâncias, devendo resolvê-los sob a pressão do tempo e de modo irreversível (Kissinger, 1994:27).

Na boca de Wechsler, porém, a exigência de que o crítico devesse se colocar, de modo adequado, no lugar do gestor para verificar suas escolhas era um claro mea culpa das ocorrências históricas precedentes em que estivera envolvido. Em 1944, o jurista chefiara a Divisão de Guerra do Departamento de Justiça dos Estados Unidos e, com isso, acabou liderando o grupo de advogados responsáveis pela elaboração da defesa do governo no caso Korematsu, processo em que se discutiu a constitucionalidade do confinamento de japoneses ou cidadãos americanos de ascendência nipônica durante a Segunda Guerra Mundial por motivo de segurança nacional. De posse de um parecer conclusivo da Agência Federal de Investigação (Federal Bureau of Investigation - FBI) que desmentia a existência de um suposto "perigo amarelo", argumento presente nos relatórios militares e utilizado intencionalmente como justificativa para a evacuação em massa de nipônicos da Costa Oeste americana e seu respectivo confinamento, Wechsler teria preferido manter sigilo sobre tal informação (Irons, 1993:286291). Assim, acabou prorrogando, sem necessidade, a existência dos "centros de realocação", termo que, segundo o próprio jurista admitiu posteriormente, era apenas um eufemismo para uma situação que, de forma adequada, poderia ser chamada de "campo de concentração" (Silber e Miller, 1993:889).

Na já mencionada conferência ministrada em 1955, Wechsler reconheceu que não deveria ter aceitado coordenar a defesa do Estado no caso Korematsu. Porém, ao mesmo tempo, 
alegou que a divisão de funções da sociedade exigia isso dele. Afinal, transcrevendo suas próprias palavras, "não era minha responsabilidade ordenar ou não ordenar a evacuação de japoneses [...], era responsabilidade do Presidente dos Estados Unidos, que tinha sido eleito pelo povo dos Estados Unidos" (Silber e Miller, 1993:890). De fato, quando Wechsler assumiu a chefia da Divisão de Guerra do Departamento de Justiça, o decreto presidencial que determinara tal ordem já havia sido expedido há anos. Porém, ao intervir posteriormente no debate judicial do caso, ele poderia ter contribuído para a extinção imediata do confinamento nipônico. No entanto, Wechsler afirmou: "não era minha responsabilidade determinar se a evacuação era constitucional ou inconstitucional. Tal responsabilidade era [...] da Suprema Corte dos Estados Unidos, composta por nove homens, indicados pelo Presidente e aprovados pelo Senado" (Silber e Miller, 1993:890).

O presente artigo considera as afirmações feitas por Wechsler como provocação para investigar a legitimidade do controle social da gestão pública: pode, afinal, um cidadão alheio aos detalhes que cercam as escolhas políticas exercer um controle social sobre o gestor público? Numa sociedade complexa, em que a estrutura do Estado se ordena de modo policêntrico, com clara distribuição de tarefas, até que ponto o gestor deve ser responsabilizado pelas ações nas quais tenha incorrido apenas de modo parcial? A democracia por si só legitima a ação de seu governante e vincula a ação dos demais gestores à orientação geral do chefe político eleito? Na busca de tais respostas, a pesquisa fará um percurso interdisciplinar: em um primeiro momento, problematizará a visão de Wechsler quanto à transparência da administração pública e quanto ao dever do gestor público de prestar contas de seus atos. Para isso, o artigo recuperará o conceito de ato ético formulado pelo filósofo russo da responsabilidade Mikhail Bakhtin, enfatizando, de modo especial, as noções de não álibi no mundo e de visão transgrediente do outro.

Na sequência, o estudo lidará com autores contemporâneos da ciência política, especialmente Andreas Schedler, para apontar como a noção de accountability é construída não apenas sobre a ideia de controle e punição, mas também sobre o parâmetro do diálogo e da socialização dos relatos da experiência administrativa. Tal perspectiva iluminará a dificuldade de se construir controles sociais efetivos em realidades não democráticas, por lhes faltar a abertura dialógica. Em seguida, o artigo retomará o papel polarizador que o chefe de governo exerce na administração pública segundo o sistema de governo adotado pelo Estado, apontando como o presidencialismo estruturalmente condiciona o corpo de servidores públicos a executar políticas de governo em detrimento de políticas de Estado. Por fim, serão apresentadas as considerações conclusivas.

\section{0 não álibi no mundo}

Na defesa que fez de sua atuação, Herbert Wechsler estruturou a gestão pública em três pilares: uma distribuição prévia de competências feita pela sociedade, uma execução das competências conferidas a cada gestor ou grupo de gestores sem interferência dos que não 
tenham sido legitimados para tanto e, por fim, uma impossibilidade de a sociedade apreciar criticamente o cumprimento das tarefas que tenha previamente distribuído. Tais pilares, porém, precisam ser tematizados na perspectiva da responsabilidade, razão por que se invoca o filósofo russo Mikhail Bakhtin. E embora, a princípio, alguns leitores possam estranhar a escolha desse autor, principalmente porque aparentemente ele nunca concluiu o capítulo prometido sobre ética na política, seus escritos sobre a estrutura dialógica da sociedade e o agir responsável do indivíduo são mais que adequados à reflexão da democracia contemporânea (Hirschkop, 1999:3).

Uma das principais preocupações de Bakhtin, presente já em seus primeiros textos, era a cisão entre a cultura e a vida, entre o inteligível e o sensível. O campo da cultura comumente cria um mundo autônomo abstratamente teórico regido por leis próprias e alheio à historicidade única e viva de cada indivíduo. A pessoa historicamente situada só penetra nesse universo por meio de um ato de abstração em que, renunciando à sua condição de ser humano individual e responsavelmente ativo, assume a posição de um sujeito epistemológico, de uma consciência universal e transcendente que opera, à perfeição, as leis imanentes desse construto teórico. Tais leis, no entanto, ou totalmente divorciadas da unicidade da vida ou apenas mecanicamente integradas a ela, acabam se tornando autorreferentes, capazes de surgir, de tempos em tempos, como uma força terrível e irresponsavelmente destrutiva (Bakhtin, 1990:1-2, 1993:24-25). O exemplo do nazismo, mesmo não contemporâneo aos primeiros textos de Bakhtin, exemplifica bem o ideal abstratamente construído que, traído pela realidade, não recua em seu propósito - ao invés de se conformar com a concretude da vida, tenta adequá-la ao seu programa teórico pretensamente perfeito.

Embora, em seu extremo, este mundo da cultura possa fazer do ser humano concreto uma figura dispensável, ele mantém um forte apelo social graças às soluções imediatas que apresenta aos problemas cotidianos dados pela complexidade da vida. O homem contemporâneo - e por consequência, no presente estudo, o gestor contemporâneo — se sente seguro e confiante quando não precisa projetar sua individualidade no mundo autônomo da cultura, esse domínio regido por leis próprias imanentes; afinal, suas ações facilmente encontram uma justificativa plausível em algum pressuposto abstratamente dado pelo campo teórico, qualquer que seja ele: jurídico, econômico, político, artístico, religioso. Porém, quando esse mesmo homem/gestor se percebe como centro emissor de ações responsáveis, repercussivas no mundo da vida, ele se torna inseguro, indeciso e inconvicto (Bakhtin, 1993:38).

Ao invocar a distribuição prévia de competência feita pela sociedade, Wechsler se escora numa legitimação totalizante e decorrente do exercício regular do direito. A delimitação dos limites de tal excludente de responsabilidade, bastante clara no mundo abstrato da teoria, não responde, todavia, às problemáticas situações imprevistas da vida concreta, momentos em que o indivíduo historicamente situado precisa se posicionar em seu agir ético. Quão responsáveis pelo Holocausto foram os maquinistas que transportaram os comboios de judeus para Auschwitz ou os fornecedores de Zyklon B, o agente químico utilizado nas câmaras de gás dos campos de concentração? Quão responsáveis foram os juristas que, a pedido de governos ditatoriais, criaram argumentos legais para a prisão, a tortura e o desaparecimento forçado de 
opositores políticos? Quão responsável foi Wechsler que, ciente da insubsistência dos motivos que levaram ao confinamento de nipônicos, acabou se mantendo silente, prorrogando, assim, uma medida sabidamente arbitrária? Para tais situações, principalmente quando ocorridas no ineditismo próprio da realidade, não há construto teórico que defina tão amiúde o conceito de exercício regular de direito e que exclua, portanto, a tomada de posição responsável do indivíduo.

Segundo Bakhtin, paralela à verdade de um conteúdo teórico regida por leis universais, há a justiça de tal proposição, a dimensão ética desse mesmo conteúdo que só se revela no contexto em que é materializada e por quem a converte em ato (Amorim, 2009:22). Por isso, o indivíduo chamado à ação não pode se escusar: primeiro, porque em seu agir consciente é que a cisão entre mundo da cultura e mundo da vida pode ser superada, na medida em que o plano acabado do conteúdo teórico é posto à prova diante da multiplicidade e da descontinuidade da realidade em devir, do concreto ainda em processo de vir-a-ser. Nesse momento, o sujeito historicamente situado, independentemente da função socialmente desempenhada, deixa de se obrigar irrefletidamente pelo conteúdo teórico de uma ordem e passa a cumpri-la por conscientemente reconhecê-la, assinando-a como igualmente sua (Bakhtin, 1993:56).

E, segundo, porque a própria existência desse agente é inescusável: afinal, se um preceito teórico é apenas uma possibilidade cuja realização depende de um ato ético baseado no reconhecimento feito por um sujeito específico, toda omissão ou toda ação imprópria precisa ser colocada na conta de quem tinha condições de agir adequadamente em razão da posição por ele ocupada, "lugar que não pode ser tomado por ninguém mais e que é impenetrável por qualquer outra pessoa" (Bakhtin, 1993:58). Tal percepção de que aquilo a ser feito por um sujeito, num dado tempo, num dado espaço, não pode ser feito por mais ninguém conduz a um permanente não álibi. Desse modo, o dever abstrato do ser humano passa a ser pensado na dimensão concreta de cada pessoa.

Isso se aplica igualmente ao gestor público. A realização de um ato político ou administrativo pressupõe uma autorização social para fazê-lo. Tal atribuição, porém, não exclui a responsabilidade pessoal do agente, apenas a especializa. Assim, longe de poder se esconder no pretenso automatismo de uma ação técnica ou instrumental, o servidor público acaba assumindo o ônus de um duplo não álibi: como sujeito, em relação à sua própria vida e aos valores universais que ele reconhece e pessoalmente ratifica, e como gestor, em relação ao Estado e aos valores específicos que a respectiva sociedade reconhece, coletivamente ratifica e que ele representa (Bakhtin, 1993:70-71).

De fato, quando Wechsler indica que, por sua posição, o presidente é quem tinha poderes para ordenar ou não ordenar a evacuação de japoneses e que cada ministro da Suprema Corte é quem poderia declarar ou não declarar a inconstitucionalidade do confinamento nipônico, fica clara a percepção de um não álibi derivado da posição que cada sujeito ocupa em um dado contexto da vida real e concreta. Porém, ao invocar tal argumento como modo de se eximir da crítica social, direcionando-a apenas aos outros, Wechsler negou o ato ético propriamente bakhtiniano, o ato responsável e assinado em que o sujeito "que pensa um pensamento assume que assim pensa face ao outro, o que quer dizer que ele responde por isso" (Amorim, 
2009:22) — reduzindo, assim, o agir a uma impostura, a uma desculpação, a um esconderijo. Afinal, cabia a Wechsler divulgar ou não divulgar as falsidades factuais identificadas nos relatórios militares utilizados como justificativa da política de confinamento de japoneses na Costa Oeste dos Estados Unidos, decisão pela qual ele, e não o presidente da República ou os ministros da Suprema Corte, é quem deveria responder.

Por fim, a unicidade de cada sujeito, que decorre de sua posição singular na realidade da vida, não significa uma impossibilidade de apreciação de seu agir. Isso fica claro pelo próprio termo com que Bakhtin formula a noção de responsabilidade: a raiz russa otvetstvennost' refere-se tanto à responsividade do ato (responder a algo ou a alguém), quanto à possibilidade de avaliação do agente em relação a seus atos (responder por algo) (Sobral, 2009:124). Com isso, o filósofo russo incluiu o não álibi na perspectiva dialógica que pautou seu pensamento: o que caracteriza a individualidade é a maneira como cada sujeito, pelo reconhecimento e pela assinatura de determinados valores sociais, responde à realidade e às pessoas com que entra em contato a partir de seu lugar no tempo e no espaço, submetendo-se, depois, às consequências de tal resposta (Clark e Holquist, 1998:90-92). Não sem motivo, na língua inglesa, o termo otvetstvennost' tem sido traduzido como answerability - considerado um equivalente linguístico mais adequado que responsibility - e, no Brasil, o neologismo respondibilidade ganhou algum consenso (Sobral, 2008:21).

Assim, o ato simultaneamente responsivo e responsável integra uma cadeia dialógica que não se inicia nem se exaure nele, razão por que qualquer reflexão sobre o mesmo não pode se restringir à percepção autocrítica de quem o praticou. Repercussivo na vida dos demais, ainda que não endereçado intencionalmente a eles, todo ato ético só pode pretender algum acabamento analítico se integrar em sua apreciação o excedente de visão que possuem os demais sujeitos historicamente situados - pois, ao ocuparem um lugar distinto na vida concreta, percebem uma fatia específica do mundo que, aos olhos do agente responsável, é imperceptível. Por isso, qualquer ato precisa ser lido na tríplice dimensão do self-para-si, do self-para-o-outro e do outro-para-o-self (Bakhtin, 1993:74-75; Pires e Sobral, 2013:212-214).

Assim, à luz do referencial bakhtiniano, quando Wechsler exige do crítico responsável que se coloque adequadamente na posição do homem cuja decisão pretenda criticar, parece que a própria possibilidade da crítica se esvai, já que o não álibi do sujeito decorre de seu lugar único na vida. A rigor, pois, nenhum cidadão pode propriamente ocupar o lugar do gestor no momento em que ele pratica o ato. Somente ele consegue esclarecer sua visão particular dos fatos envolvidos, assim como os valores universais da cultura jurídica, política ou econômica por ele reconhecidos e materializáveis na efetivação do ato responsável. Pensar o contrário seria substituir pura e simplesmente o agir do gestor pelo agir do cidadão. Porém, longe de impossibilitar a crítica, tal percepção só a torna mais complexa e profícua, pois partindo desse esclarecimento cuja publicização cabe ao gestor, pode cada cidadão, a partir de seu próprio excedente de visão, complementar a análise do ato, levando em conta a contraposição entre os fatos de que tinha ciência o gestor e a população em geral, bem como os valores a que a administração deu preeminência. A crítica legítima não se produz, pois, com exclusividade 
nas mãos do gestor ou do analista político, mas na prática dialógica de uma gestão administrativa democrática.

Nessa perspectiva, os três pilares da gestão pública invocados por Wechsler em sua defesa, longe de livrá-lo da responsabilidade dialógica com a sociedade civil, acabam reforçando-a: a distribuição prévia de competências feita pela sociedade, perfeitamente concatenada como esquema ideal, não exclui a responsabilidade do gestor na tomada de posição cotidiana, quando o ineditismo dos problemas complexos não encontra resposta fácil na abstração do campo teórico; a execução das competências por cada gestor, agindo como representante do povo, por não anular sua responsabilidade pessoal, não serve como escusa; por fim, embora ninguém possa efetivamente ocupar o lugar confiado ao gestor público na resolução de um problema, isso não impede a crítica que necessariamente se constrói na contraposição de visões complementares de um mesmo evento.

Desse modo, o não álibi do sujeito, fruto de sua unicidade na vida e de sua posição exclusiva no tempo e espaço, acaba exigindo do gestor uma exposição dos motivos determinantes dos atos que efetiva. Do contrário, a crítica e o controle social são obstacularizados. Daí a construção contemporânea da accountability ter se estruturado na perspectiva de uma racionalidade discursiva, chegando, por outros caminhos, às mesmas propostas pensadas pela filosofia da responsabilidade de Mikhail Bakhtin.

\section{Dialogismo e responsabilização}

Independentemente do regime de governo, sempre existe uma margem de poder discricionário nas mãos do governante que permanece refratária à prévia regulação burocrática. Além disso, por mais transparente que seja a prática política, dificilmente a assimetria informacional existente entre governantes e governados é completamente superada, o que decorre da própria opacidade do poder — afinal, todo arranjo institucional garante certos espaços de confidencialidade legítima em que decisões são discutidas e planejadas de modo restrito antes de vir a público (Schedler, 1999:21). Ocorre, porém, que, em Estados de exceção, a discricionariedade exercida pelos governos e a informação privilegiada que eles detêm não estão sujeitas a um controle socialmente ampliado e procedimentalmente imparcial. A democracia, por outro lado, costuma garantir meios hábeis à fiscalização, quer para exigir do governante uma resposta aos questionamentos postos pela sociedade sobre os motivos dos atos de gestão por ele adotados, quer para responsabilizá-lo pelos excessos e desmandos em que tenha incorrido na condição de gestor.

Esta dupla dimensão do controle social, que em grande parte parece trilhar um caminho bastante próximo ao da perspectiva responsiva e responsável do ato ético em Mikhail Bakhtin, foi identificada por Andreas Schedler como constituidora da atual accountability. Tal abordagem, se não facilitou a tradução literal para o português desse anglicismo, ao menos conseguiu torná-lo mais compreensível, principalmente pelo método de considerá-lo, a cada vez, pela ótica de um de seus dois pilares. O primeiro pilar, chamado por Schedler de 
answerability, é fortemente marcado por um viés dialógico: o dever do gestor de responder às perguntas formuladas pelos afetados por sua gestão e o direito destes de formulá-las (Schedler, 1999:14).

A maneira como tais perguntas são formuladas podem indicar dois tipos de respostas, ambas igualmente exigíveis: as informativas e as explicativas. A dimensão informacional refere-se à obtenção dos dados indispensáveis ao monitoramento objetivo da gestão pública, como os necessários à contraposição entre o fluxo de caixa consolidado no relatório de execução orçamentária e o montante de receitas e despesas previamente estimadas na lei anual do orçamento - o que reforça o rule of law. A dimensão argumentativa, por outro lado, envolve o debate público sobre os motivos pelos quais as decisões foram tomadas, estabelecendo um monitoramento discursivo da gestão pública e promovendo o rule of reason. Desse modo, a answerability seria totalmente incompatível tanto com um poder mudo que tomasse decisões sem justificá-las quanto com um poder monológico que adotasse uma postura discursiva unilateral (Schedler, 1999:14-15).

A democracia, nessa perspectiva, seria o regime de governo mais adequado ao controle social da gestão pública. Porém, mesmo em Estados democráticos, a manutenção de canais ampliados e inclusivos de diálogo ainda é um desafio. A accountability horizontal, decorrente do sistema de freios e contrapesos e por meio do qual as agências estatais são reciprocamente supervisionadas, acaba envolvendo Executivo, Legislativo, Judiciário e, em desenhos institucionais mais contemporâneos, os órgãos fiscalizadores das prestações de contas e os ombudspersons - em resumo, apenas entes estatais, instituições que, em algum grau, representam (e substituem) os governados (O'Donnell, 1998:42-43).

Por outro lado, a accountability vertical, forma de controle realizado pela própria sociedade civil, costuma se restringir às eleições, às reivindicações sociais e à cobertura da mídia de tais pretensões populares e dos atos praticados pelos gestores. As eleições, além de serem intercaladas por longos intervalos temporais, têm sua eficácia diluída por vários fatores, tais como sistemas partidários pouco estruturados, alta volatilidade de partidos e eleitores, e agenda política normalmente casuística. Em relação às reivindicações sociais e à cobertura da mídia, embora possam gerar um clima desfavorável ao governante tanto para a aprovação de políticas públicas quanto para a manutenção de seu grupo político no poder, poucas vezes conseguem efetivamente desencadear procedimentos públicos apropriados de responsabilização dos maus gestores (O’Donnell, 1998:28-30).

Por isso, ganhou terreno a proposta da accountability diagonal, uma forma híbrida que busca garantir à sociedade civil o acesso continuado a informações governamentais detalhadas por meio de sua inclusão nas estruturas de controle horizontal (O’Brien, 2008:111), fazendo, assim, com que os cidadãos possam se tornar ativos reivindicadores de answerability em espaços institucionalmente legitimados para a responsabilização do gestor (Goetz e Jenkins, 2001:368). Os governados, nessa proposta de diagonalidade, acabam sendo empoderados nos dois pilares do controle social da gestão pública: de modo direto, no acesso aos dados e às motivações dos atos político-administrativos do Estado; de modo indireto, naquilo que, segundo Schedler, corresponderia à segunda dimensão desse controle, o enforcement ou penalização. 
A capacidade de punir, esse outro pilar da accountability, resguarda a efetividade do monitoramento do gestor e depende de órgãos de julgamento independentes e de uma legislação prévia que preveja um leque ampliado de sanções proporcionais ao dano provocado pelo agente estatal. Em alguns países, a exposição pública dos equívocos da gestão já seria uma punição suficiente, na medida em que minaria o capital político do governante e sua possível permanência no poder. A Comissão da Verdade da África do Sul, por exemplo, órgão criado numa perspectiva de justiça transicional, optou por exigir para muitos dos casos de excessos praticados durante o regime de apartheid apenas uma retratação pública do agente responsável. Porém, em Estados com pouco amadurecimento democrático, as penas de perda do cargo, de inelegibilidade por um certo lapso temporal e de ressarcimento em dobro dos cofres públicos parecem condenações mais adequadas ao desestímulo de uma administração corrupta ou propositadamente negligente. Por fim, para casos extremos, como violações de direitos humanos, a responsabilização criminal nunca deve ser excluída. Afinal, um Estado democrático de direito só se afirma se os abusos de autoridade puderem ser efetivamente punidos (Schedler, 1999:16-17).

A proposta dos dois pilares de Schedler, todavia, parece incompatível com, ao menos, um teórico da filosofia moral. Segundo David Shoemaker (2011), existiriam três tipos distintos de responsabilidade moral que, somente quando conjugadas, seriam capazes de cobrir o espectro total da conduta humana: answerability, que exigiria do agente as razões justificadoras de suas ações; attributability, relacionada com os atos para os quais o agente não teria uma explicação plausível, como aqueles realizados por motivação irracional ou puramente emotiva, mas pelos quais, mesmo assim, seria responsável; e accountability, referente aos atos passíveis de sanção por terem gerado algum tipo de dano moral ou material. Segundo tal perspectiva, o fundamento dialógico do controle social da gestão pública perderia bastante de sua legitimação ou, ao menos, ficaria enfraquecido ao ser divorciado da dimensão punitiva. Além disso, considerando que o campo do político é propício à manifestação das paixões (Mouffe, 2005:21-25), a emergência de atos passionais na esfera pública, sujeitos a um tipo de responsabilidade não argumentativa, acabaria comprometendo os esforços de consolidação de uma racionalidade democrática.

Por isso, a defesa de Angela Smith de uma teoria unificada da responsabilidade merece menção. Em sua reação a Shoemaker, Smith (2012) argumenta que não seria possível classificar uma conduta como answerable ou accountable apenas depois de praticada, utilizando um critério que considerasse menos a ação em si do que o tratamento conferido pelo outro, voltado ou para a continuidade dialógica ou para a punição imediata. Toda ação já seria previamente sujeita à respondibilidade por sua própria natureza - e uma resposta mais severa dependeria tanto do dano causado pela conduta do agente quanto pela ausência de motivos suficientemente legítimos.

Além disso, contrariamente ao senso comum, seria sim possível exigir, mesmo da irracionalidade, alguma responsabilidade argumentativa. Assim, embora não pudesse ser exigida do sujeito com graves problemas psíquicos uma explicação justificada de suas ações, sendo pois irresponsável quanto a elas, o mesmo não valeria para aquele que em pleno uso de suas 
faculdades mentais mantivesse posturas mutuamente incompatíveis, reveladoras, em seu conjunto, de uma não plausibilidade. Na genuína irracionalidade, não são as condutas isoladas que são consideradas inválidas, mas sim sua articulação. O indivíduo, por exemplo, que tem medo de aranhas mesmo sabendo que elas são inofensivas acaba mantendo um pensamento irracional, pois tais assertivas, quando analisadas em conjunto, são mutuamente excludentes. Pelas atitudes que, somadas, constituem uma irracionalidade é que o sujeito seria, então, responsável - o que invalidaria uma defesa da atributabilidade como opositora da respondibilidade (Smith, 2012: 578-580).

Tal debate não é meramente teórico. E isso fica bastante claro quando Smith, ao exemplificar seu argumento, equipara o racismo a um pensamento irracional - mesmo que não genuíno, pois na maioria das vezes seria possível objetar cada uma das atitudes isoladas que integram a conduta discriminatória. Disso decorreria que todo sujeito de uma ação discriminatória racial não só deveria ser responsabilizado, mas também chamado a dar respostas públicas de sua incoerência — o que, sem dúvida, criaria um efeito legitimador da punição no presente e fomentaria um aprendizado sociopedagógico para as gerações futuras. Tal exemplo concreto, aliás, acaba conduzindo o texto de volta ao caso Korematsu. A conduta ordeira e pacífica dos japoneses que residiam nos Estados Unidos desde fins do século XIX era incompatível com o argumento de que punham em risco a segurança nacional. Logo, a lógica do "perigo amarelo interno" era irracional (United, 1982). Com os ataques a Pearl Harbor, era possível considerar que os japoneses haviam se tornado inimigos - mas não os nipônicos ou americanos de ascendência japonesa residentes em solo estadunidense que não possuíam qualquer relação com o bombardeio.

Por isso, a disseminação de "falsidades intencionais" pelos relatórios militares acabou produzindo uma aparência de racionalidade para as ações de evacuação e realocação. Ao saber de tais falsidades e optar por ocultá-las, Wechsler também passou a se sujeitar ao controle social por tal política de segurança nacional. Retomando os parâmetros de Schedler, quanto ao pilar da answerability, o jurista não prestou informações nem aos governados nem às instâncias de responsabilização sobre o relatório elaborado pela Agência Federal de Investigação que indicava serem falsas as provas de atos de espionagem constantes do relatório militar, ofendendo, pois, a dimensão informacional da accountability. Além disso, garantiu a manutenção da política de encarceramento valendo-se de uma justificação enganosa ou, ao menos, incongruente, caso entendesse que, apesar dos falsos indícios, haveria algum "perigo amarelo" interno. Sem poder invocar nem mesmo a influência do temor irracional da época, porque claramente incoerente com a realidade fática verificável, ele igualmente ofendeu à dimensão argumentativa da accountability. Por tudo isso, o pilar do enforcement ficou prejudicado ou, ao menos, temporalmente postergado, pois apenas com o passar dos anos tornou-se claro quão punível poderia ter sido a conduta de Wechsler.

Pode-se objetar, porém, que, em tal ambiente fortemente marcado por um terror irracional, mesmo uma estrutura de controle diagonal não teria sido capaz de romper com a omissão do discurso oficial, na medida em que os representantes majoritários da sociedade civil provavelmente ratificariam as decisões governamentais em nome da segurança nacional. 
Isso, porém, longe de invalidar a accountability, a aperfeiçoa: sinal de que a representação da sociedade civil nas estruturas de controle da gestão pública deve observar um critério amplo e plural, com garantia de acesso a todo espectro social e, em especial, às minorias. Nesse panorama, o coletivo dos cidadãos em sua heterogeneidade teria cada vez mais condições de realizar aquilo que Wechsler denominou de crítica responsável: uma apreciação das escolhas feitas pelo gestor considerando tanto as informações acessíveis quanto os recursos disponíveis no momento da decisão.

\section{0 desafio democrático e os sistemas de governo}

Ao responder às críticas de que ficara silente ante a constatação de que uma política de restrição de direitos se baseava em falsidades intencionalmente plantadas em documentos oficiais, Herbert Wechsler alegou que não podia se contrapor a uma determinação do presidente, chefe político legitimamente eleito pelo voto popular. O argumento do jurista estadunidense acabou revelando quão variável é a efetividade de um controle social da gestão pública conforme o sistema de governo adotado pelo país. Não sem motivo, no início dos anos 1990, Juan Linz (1990a, 1990b) deflagrou um debate sobre os perigos do presidencialismo e as virtudes do parlamentarismo. Segundo Linz, o presidencialismo apresentava vários pontos negativos: os mandatos fixos infensos às mudanças contínuas que os acontecimentos normalmente exigem, o controle pleno da composição do gabinete e da administração decorrente de uma política de soma zero em que o vencedor das eleições "ganha tudo", uma legitimidade dual dividida entre Executivo e Legislativo que, em casos de não acomodação madisoniana, leva à ruptura do sistema, e uma lógica contraditória que fraciona e justapõe na figura do presidente os papéis de chefe de governo, chefe simbólico do Estado e membro de um partido político cujo programa pretende implementar. Tais vícios, segundo Linz, seriam superados em um sistema parlamentarista.

As reações a Linz foram diversas: Horowitz (1990) criticou o limitado recorte exemplificativo que enfatizava países latino-americanos e a utilização de um tipo ideal de presidencialismo que não levava em conta as especificidades do sistema eleitoral de cada Estado; tal crítica foi potencializada com os textos de Shugart e Carey (1992), Mainwaring (1993) e Lijphart (1995), que reclamavam a inclusão de outras variáveis em tais análises, como a extensão dos poderes confiados ao presidente e a influência do sistema partidário adotado, e relativizavam a existência de modelos únicos e rigidamente estabelecidos de presidencialismo e parlamentarismo. De modo geral, porém, as críticas acabavam conduzindo a um reforço do parlamentarismo como o sistema de governo mais propício a estabilizar a democracia.

À mesma conclusão chegou Ackerman, para quem o êxito do presidencialismo nos Estados Unidos seria uma exceção explicada pelas especificidades locais. Em artigo no qual condensou uma década de debates, Ackerman abordou, entre outros aspectos, a maneira como os distintos sistemas de governo moldam a prática administrativa de seus respectivos servidores (bureaucrats). Comparando os modelos americano e britânico, seria possível perceber que os 
servidores de um sistema presidencialista lidam, a todo tempo, com um jogo político entranhado na burocracia, de tal modo que não diferenciam claramente a natureza da sua função em relação àquela desempenhada pelos agentes eleitos (Ackerman, 2000:699-700).

Como a eleição do presidente é desvinculada da eleição de deputados e senadores, o loteamento de ministérios, secretarias e órgãos da administração indireta entre partidos da base aliada, prática utilizada com o fim de angariar maioria legislativa, cria uma situação em que o servidor se equilibra entre projetos divergentes de partidos políticos unidos apenas de modo contingencial — de tal maneira que sua atuação oscila entre prioridades difusamente apontadas. Uma accountability horizontal ainda mais fragmentada pelo jogo político de um sistema presidencialista forçaria os servidores a defenderem, primeiramente, seus próprios interesses, empregos, gratificações, cargos de confiança para, só então, atenderem ao interesse do Estado - o que fomentaria um verdadeiro resquício de patrimonialismo, cuja presença no Brasil, por exemplo, já foi várias vezes analisada (Bresser-Pereira, 2001; Abrucio, Pedroti e Pó, 2010).

Tal sistema de nomeações em segundo e terceiro escalão de governos presidencialistas geraria ainda outra consequência. A cada novo governo a quantidade de exonerações e novas nomeações seria bastante numerosa, quer pela necessidade de acomodar os novos grupos políticos apoiadores na estrutura burocrática, quer para se precaver da existência de servidores remanescentes fiéis a grupos políticos derrotados que, enclausurados em seus departamentos, poderiam minar as forças do novo governo. Em um sistema parlamentarista como o britânico, a eleição de um primeiro ministro já pressuporia um implícito apoio parlamentar que, se não obtido nas próprias eleições, costuma ser fruto de um acordo político único e necessário, prévio à própria posse, que suscita uma coligação com a maioria das cadeiras do Legislativo. Em tais contextos, os servidores públicos conseguem garantir uma continuidade mais frequente de suas atividades técnicas, mensuradas pela expertise e não por alguma sujeição política (Ackerman, 2000:701-702).

Quando Wechsler se negou a atuar conforme o padrão esperado de um burocrata probo que, ciente da ausência de motivação para um determinado agir administrativo, leva o fato a conhecimento imediato de seus superiores e toma as providências cautelares necessárias para evitar maiores prejuízos ao cidadão, ele acabou reforçando a fragilidade de controle do sistema presidencialista, ao invés de justificar sua própria ação — o que só justifica a necessidade de uma crítica cidadã ainda mais vigilante. A politização da burocracia é um claro forjador de habitus patrimonialista, por meio do qual o servidor busca preservar pelo maior tempo possível a condição favorável que desfruta pela posição ocupada, desconsiderando o não álibi individual e os padrões objetivos de moralidade administrativa.

Tal situação é ainda mais potencializada em democracias nas quais o presidente eleito é "autorizado a governar o país como lhe parecer conveniente" sem a exigência de espelhar fielmente o que "disse ou prometeu durante a campanha eleitoral", modelo chamado, por O’Donnell (1991:30), de democracia delegativa. Ou ainda, em sistemas presidencialistas nos quais a figura presidencial acumula os poderes de declarar o estado de exceção, de intervir nas unidades subnacionais, de vetar projetos de lei por motivação política pouco sindicável, de nomear e exonerar a seu critério os ministros de seu gabinete, de participar da nomeação 
de agentes dos órgãos de controle, de exercer funções legislativas adicionais de modo não delegado em situações de urgência — modelo chamado, por Nino (1992:504-530; 625-652), de hiperpresidencialismo. Em ambas as situações, bastante comuns na América Latina, há um grande risco de que o presidencialismo produza um culto à personalidade do governante, merecedor dos holofotes e, quando muito, de um accountability vertical retrospectivo por ocasião das eleições subsequentes, restando obscurecidas e deficitárias as outras dimensões de controle da gestão pública e enfraquecidas as instituições democráticas (Moreno, Crisp e Shugart, 2003:79-131).

Assim, considerando o exemplo brasileiro, quando Anna Maria Campos questionou, em 1987, os motivos pelos quais o termo accountability não era recepcionado naquele momento pela administração pública brasileira, nem como tradução, nem como conceito, era de se esperar uma conclusão que, de algum modo, conduzisse à tradição autoritária/populista da democracia nacional. A uma subcidadania geralmente correspondeu uma sobre-estatalidade, quer pela prática ditatorial de definir com exclusão do cidadão o parâmetro ideal de bem-estar social, quer pela prática populista de se relacionar diretamente com ele, de modo atomista, enfraquecendo instituições e instâncias organizadas para realizar tal diálogo de modo menos assimétrico (Campos, 1990:36-38).

A Constituição de 1988 não foi capaz de romper totalmente com tal tradição. Embora tenha constituído um projeto de federalismo cooperativo, com compartilhamento de competências entre todos os entes federados, quais sejam, União, estados, Distrito Federal e municípios, bem como repartição de parte das receitas federais com os governos subnacionais, não reduziu a força e a extensão do poder central, ainda marcado por um viés hiperpresidencialista e financeiramente sustentado pelas contribuições sociais de manejo exclusivamente federal - o que levou a democracia brasileira a vários movimentos pendulares entre os polos da centralização e da descentralização durante o processo de redemocratização (Almeida, 2005; Bolonha, Rangel e Corrêa, 2015).

Não devem ser desconsiderados, por óbvio, os avanços graduais estabelecidos na vivência democrática recente. Podem ser elencados: a crescente participação popular na formulação das políticas públicas e elaboração de orçamentos, apesar das reações contrárias ao Decreto no 8.243, de 23 de maio de 2014, que instituiu a Política Nacional de Participação Social e o Sistema Nacional de Participação Social; a aprovação da Lei Complementar no 101, de 4 de maio de 2000, conhecida como Lei de Responsabilidade Fiscal, que passou a estabelecer parâmetros para a gestão das receitas, despesas e dívidas públicas, apontando para o planejamento da gestão estatal e a responsabilização pelo seu descumprimento; a criação do Conselho Nacional da Justiça, por meio da Reforma do Judiciário viabilizada pela Emenda Constitucional no 45 , de 31 de dezembro de 2004, órgão com poderes de fiscalização administrativa, financeira e funcional; a Lei no 12.527, de 18 de novembro de 2011, conhecida como Lei de Acesso à Informação, que provocou a gestão pública a implementar um modelo de transparência ativa (Pinho e Sacramento, 2009).

A questão que remanesce é se tais avanços, que fazem do controle social da gestão pública uma obra em elaboração, são suficientes em face dos vícios estruturais inerentes ao 
sistema de governo presidencialista. Não sem motivo, em razão das denúncias de corrupção em rede e má gestão da coisa pública surgidas nos últimos anos, têm sido aventadas propostas de implementação de um novo sistema parlamentarista ou semipresidencialista - que, espera-se, não se faça pelo Legislativo sem prévia consulta plebiscitária, em respeito à oitiva popular realizada em 1993. De qualquer modo, independentemente do desenrolar dos eventos, Wechsler não pode ter razão em uma democracia accountable: afinal, o parâmetro político do agente eletivo não pode pautar a conduta técnica dos demais gestores públicos.

\section{Considerações finais}

Em 1982, a Comissão sobre Realocação em Tempo de Guerra e Internamento de Civis, criada no âmbito do Congresso Nacional dos Estados Unidos, finalmente reconheceu que a política de internação de japoneses e nipodescendentes durante a Segunda Guerra Mundial não tinha sido adotada por motivos de segurança nacional, mas sim por questões de "discriminação racial, histeria de guerra e falta de liderança política" (United, 1982:18). Embora tal relatório tenha reabilitado a comunidade japonesa, ele não invalidou, de imediato, todos os efeitos gerados pelo caso Korematsu, declarado constitucional pela Suprema Corte em 1944 graças à omissão de Wechsler. Afinal, durante a Guerra Fria, tal precedente foi invocado para justificar a deportação de estrangeiros residentes nos Estados Unidos que tivessem tido quaisquer vínculos com o Partido Comunista; e, por décadas, inclusive no pós-11 de Setembro, reforçou uma teoria geral dos poderes do Executivo em épocas de crise ou de guerra, incluindo a possibilidade de supressão de direitos individuais em prol da defesa do Estado (Hashimoto, 1996:85-87; Green, 2011:1001-1032).

Por tudo isso, o caso Korematsu acaba demonstrando a importância da accountability, mesmo que tardia. Quanto à answerability, a revelação das reais bases sobre as quais se construiu uma vexatória e desnecessária política de segurança nacional permitiu que se estabelecesse um diálogo mais transparente entre governo e cidadãos, especialmente quanto à ilegitimidade do uso judicial de tal precedente (Green, 2011; Tushnet, 2003; Yamamoto, 1986). Quanto ao enforcement, além da exposição pública do nome dos gestores envolvidos no falseamento de informações ocorrido na implantação e na defesa judicial do programa de evacuação de japoneses durante a Segunda Guerra, houve uma responsabilização financeira do Estado, chamado a indenizar em 20 mil dólares cada vítima sobrevivente de tal encarceramento (United, 1988:906).

A própria democracia estadunidense, de modo intergeracional, acabou reconhecendo que Wechsler estava equivocado. Afinal, cada agente público deve responder por sua atuação, de modo individual, independentemente do sistema de governo e da orientação política do agente eletivo, pelos atos que desenvolve na gestão do patrimônio nacional, sujeitando suas decisões ao exame crítico e legítimo feito pelos cidadãos, em um processo contínuo de revisão das prioridades do planejamento governamental. 
De tudo isso, resta uma lição bastante oportuna para o Brasil. Considerando sua história recente, marcada pela opacidade administrativa do regime militar, as demandas por justiça transicional devem levar em conta o papel de uma accountability extemporânea, capaz de superar a posteriori a leniência cristalizada quanto à atuação irresponsável e monológica de governantes e gestores passados. Quanto ao presente, época de negligência política com o erário e de descrédito popular nas propostas partidárias, a saída não se encontra na intolerância e na supressão da ordem democrática, mas sim na efetivação de uma gestão cada vez mais compartilhada entre governantes e governados, na manutenção de um diálogo aberto entre gestão e sociedade civil, no aperfeiçoamento do sistema de governo presidencialista e no controle social simultâneo e permanente das políticas públicas.

\section{Referências}

ABRUCIO, Fernando Luiz; PEDROTI, Paula; PÓ, Marcus Vinicius. A formação da burocracia brasileira: a trajetória e o significado das reformas administrativas. In: LOUREIRO, Maria Rita; ABRUCIO, Fernando Luiz; PACHECO, Regina S. (Org.). Burocracia e política no Brasil: desafios para a ordem democrática no século XXI. São Paulo: FGV, 2010. p. 27-71.

ACKERMAN, Bruce. The new separation of powers. Harvard Law Review, v. 113, n. 3, p. 633-725, jan. 2000.

ALMEIDA, Maria Hermínia T. de. Recentralizando a federação? Revista de Sociologia e Política, n. 24, p. 29-40, jun. 2005.

AMORIM, Marilia. Para uma filosofia do ato: "válido e inserido no contexto". In: BRAIT, Beth (Org.). Bakhtin, dialogismo e polifonia. São Paulo: Contexto, 2009. p. 17-43.

BAKHTIN, Mikhail M. Art and answerability. In: HOLQUIST, Michael; LIAPUNOV, Vadim (Ed.). Art and answerability: early philosophical essays. Austin: University of Texas Press, 1990. p. 1-3.

BAKHTIN, Mikhail M. Toward a philosophy of the act. Austin: University of Texas Press, 1993.

BOLONHA, Carlos; RANGEL, Henrique; CORRÊA, Flávio. Hiperpresidencialismo na América Latina. Revista da Faculdade de Direito - UFPR, v. 60, n. 2, p. 115-140, maio/ago. 2015.

BRESSER-PEREIRA, Luiz Carlos. Do Estado patrimonial ao gerencial. In: PINHEIRO, Paulo S.; SACHS, Ignacy; WILHEIM, Jorge (Org.). Brasil: um século de transformações. São Paulo: Companhia das Letras, 2001. p. 222-259.

CAMPOS, Anna Maria. Accountability: quando poderemos traduzi-la para o português? Rev. Adm. Pública, v. 24, n. 2, p. 30-50, fev./abr. 1990.

CLARK, Katerina; HOLQUIST, Michael. A arquitetônica da respondibilidade. In: CLARK, Katerina; HOLQUIST, Michael. Mikhail Bakhtin. São Paulo: Perspectiva, 1998. p. 89-116.

DONALD, David H. Lincoln. Nova York: Simon \& Schuster, 1995. 
GOETZ, Anne Marie; JENKINS, Rob. Hybrid forms of accountability: citizen engagement in institutions of public sector oversight in India. Public Management Review, v. 3, n. 3, p. 363-383, 2001.

GREEN, Craig. Ending the Korematsu era: an early view from the war on terror cases. Northwestern University Law Review, v. 105, n. 3, p. 983-1041, 2011.

HASHIMOTO, Dean M. The legacy of Korematsu v. United States: a dangerous narrative retold. Ucla Asian Pacific American Law Journal, v. 4, p. 72-128, 1996.

HIRSCHKOP, Ken. Mikhail Bakhtin: an aesthetic for democracy. Nova York; Oxford: Oxford University Press, 1999.

HOROWITZ, Donald L. Comparing democratic systems. Journal of Democracy, v. 1, n. 4, p. 73-79, fall 1990.

IRONS, Peter H. Justice at war: the story of the Japanese American internment cases. Berkeley, Los Angeles: University of California Press, 1993.

KISSINGER, Henry. Diplomacy. Nova York: Simon \& Schuster, 1994.

LIJPHART, Arend. The virtues of parliamentarism: but which kind of parliamentarism? In: CHEHABI, Houchang E.; STEPAN, Alfred (Ed.). Politics, society and democracy: comparative studies. Boulder: Westview Press, 1995. p. 363-373.

LINZ, Juan J. The perils of presidentialism. Journal of Democracy, v. 1, n. 1, p. 51-69, winter 1990a. LINZ, Juan J. The virtues os parliamentarism. Journal of Democracy, v. 1, n. 4, p. 84-91, fall 1990b. MAINWARING, Scott. Presidentialism, multipartism, and democracy: the difficult combination. Comparative Political Studies, v. 26, n. 2, p. 198-228, 1993.

MORENO, Erika; CRISP, Brian F.; SHUGART, Matthew S. The accountability deficit in Latin America. In: MAINWARING, Scott; WELNA, Christopher. Democratic accountability in Latin America. Oxford: Oxford University Press, 2003. p. 79-131.

MOUFFE, Chantal. On the political. Londres; Nova York: Routledge, 2005.

NINO, Carlos S. Fundamentos de derecho constitucional: análisis filosófico, jurídico y politológico de la práctica constitucional. Buenos Aires: Astrea, 1992.

O'BRIEN, Mitchell. Social accountability - citizens, civil society, and the media working with Parliament to prevent conflict and reduce poverty. In: O'BRIEN, Mitchell; STAPENHURST, Rick; JOHNSTON, Niall. Parliaments as peacebuilders in conflict-affected countries. Washington: The World Bank, 2008. p. 105-120.

O’DONNELL, Guillermo. Accountability horizontal e novas poliarquias. Lua Nova, n. 44, p. 27-52, 1998.

O’DONNELL, Guillermo. Democracia delegativa? Novos Estudos Cebrap, n. 31, p. 25-40, out. 1991. PINHO, José Antônio G. de; SACRAMENTO, Ana Rita S. Accountability: já podemos traduzi-la para o português? Rev. Adm. Pública, v. 43, n. 6, p. 1343-1368, nov./dez. 2009. 
PIRES, Vera L.; SOBRAL, Adail. Implicações do estatuto ontológico do sujeito na teoria discursiva do Círculo Bakhtin, Medvedev, Voloshínov. Bakhtiniana, v. 8, n. 1, p. 205-219, jan./jun. 2013.

SCHEDLER, Andreas. Conceptualizing accountability. In: SCHEDLER, Andreas; DIAMOND, Larry; PLATTNER, Marc F. (Ed.). The self-restraining State: power and accountability in new democracies. Boulder; Londres: Lynne Rienner Publishers, 1999. p. 13-28.

SHOEMAKER, David. Attributability, answerability, and accountability: toward a wider theory of moral responsibility. Ethics, v. 121, n. 3, p. 602-632, abr. 2011.

SHUGART, Matthew S.; CAREY, John M. Presidents and assemblies: constitutional design and electoral dynamics. Cambridge: Cambridge University Press, 1992.

SILBER, Norman; MILLER, Geoffrey. Toward "neutral principles" in the law: selections from the oral history of Herbert Wechsler. Columbia Law Review, v. 93, n. 4, p. 854-931, maio 1993.

SMITH, Angela M. Attributability, answerability, and accountability: in defense of a unified account. Ethics, v. 122, n. 3, p. 575-589, abr. 2012.

SOBRAL, Adail U. Ato/atividade e evento. In: BRAIT, Beth (Org.). Bakhtin: conceitos-chave. São Paulo: Contexto, 2008. p. 11-35.

SOBRAL, Adail U. O conceito de ato ético de Bakhtin e a responsabilidade moral do sujeito. Bioethikos, v. 3, n. 1, p. 121-126, jan./jun. 2009.

TUSHNET, Mark V. Defending Korematsu? Reflections on civil liberties in wartime. Wisconsin Law Review, v. 2003, n. 2, p. 273-307, 2003.

UNITED States of America. Personal justice denied: report of the Comission on Wartime Relocation and Internment of Civilians. Washington: U.S. Government Printing Office, 1982.

UNITED States of America. Public Law 100-383 - Aug. 10, 1988 (Civil Liberties Act of 1988). United States Statutes at Large, Washington, v. 102, p. 903-911, 1988.

WECHSLER, Herbert. Some issues for the lawyer. In: MCIVER, Robert M. (Ed.). Integrity and compromise: problems of public and private conscience. Nova York: Harper \& Brothers, 1957. p. 117-128.

YAMAMOTO, Eric K. Korematsu revisited - correcting the injustice of extraordinary government excess and lax judicial review: time for a better accommodation of national security concerns and civil liberties. Santa Clara Law Review, v. 26, n. 1, p. 1-62, 1986.

Douglas Antônio Rocha Pinheiro é doutor em direito, Estado e Constituição pela Universidade de Brasília (UnB) e professor adjunto do Programa de Pós-Graduação Interdisciplinar em Direitos Humanos da Universidade Federal de Goiás (UFG). E-mail: darpinheiro@gmail.com. 